\title{
CIDADES INTELIGENTES inovação tecnológica no meio urbano
}

Fábio Duarte

\footnotetext{
Resumo: Neste artigo analisa-se como o desenvolvimento dos pólos de inovação tecnológica pode ser incorporado nos processos de gestão urbana, especialmente em projetos de recuperação de áreas urbanas.

Palavras-chave: Inovação tecnológica. Arranjos produtivos locais. Gestão urbana.

\begin{abstract}
In this article we analyze how the development of regions of technological innovation within the cities can be appropriated into the urban management process, making these innovation poles catalytic to projects of recovery of urban areas.

Key words: Technological innovation. Local productive arrangements. Urban management.
\end{abstract}

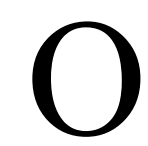

s pólos tecnológicos são comumente analisados pela inserção de processos produtivos inovadores, pela articulação de atores científicos, empresariais, financeiros e políticos e pelos arranjos econômicos locais. Grande parte desses pólos é implantada em meios urbanos que, por despreparo ou desarticulação dos organismos públicos locais, da iniciativa privada e dos centros de pesquisa, perdem oportunidades de torná-los catalisadores de requalificação de áreas urbanas.

Destacam-se, nesta análise, os aspectos dos processos de inovação que trazem conseqüências para a gestão urbana, buscando saber como é possível otimizar valores de um contexto urbano central de modo a atrair a implantação de um pólo de inovação tecnológica e torná-lo, ao mesmo tempo, catalisador de requalificação urbana.

Como estudo de caso, tomou-se a Cidade Multimídia, desenvolvida a partir de 1998 em região central degrada- da de Montreal. Para isso, analisaram-se seus planos de implementação tecnológica, econômica, política e urbana; foram realizadas visitas técnicas à região; entrevistaram-se responsáveis por órgãos públicos, empresas e institutos de pesquisa envolvidos e estudou-se material científico e jornalístico, em que especialistas debateram $\mathrm{o}$ assunto.

O foco de todos os esforços se manteve nas estratégias urbanas adotadas para a implantação do pólo e nos instrumentos decisórios e de gestão envolvendo as empresas, a universidade e a cidade, resultando em uma análise dos impactos sociais, culturais e urbanos conseqüentes do processo de planejamento e implantação adotado.

Demonstra-se que a articulação de políticas nacionais e provinciais com objetivos claros de desenvolvimento socioeconômico ligado a um ramo tecnológico inovador, o diagnóstico de oportunidades de mercado e o envol- 
vimento da escala municipal na atração de determinado tipo de empresa para uma região específica da cidade e na articulação com outros atores, como investidores imobiliários e universidades, podem fazer com que, mais do que apenas um receptáculo, a cidade torne-se a catalisadora do desenvolvimento de um pólo tecnológico inovador tanto pela economia tecnológica quanto pela recuperação de um contexto urbano.

\section{A CIDADE NA SOCIEDADE INFORMACIONAL}

Parte-se da reflexão de que a sociedade contemporânea é construída com base nas tecnologias de informação, responsáveis tanto pelos produtos característicos da épo$\mathrm{ca}$ - sejam eles independentes (como softwares), parte de produtos tecnológicos (de veículos a eletrodomésticos) ou commodities (alimentos geneticamente modificados) quanto pelos processos de fabricação e gerenciamento de produção, distribuição e venda dos produtos (CASTELLS, 1996; SANTOS, 1996). Nessa sociedade, caracterizada pelos fluxos de informação organizados em redes flexíveis e mutantes, colocam-se duas questões:

- Qual a importância das cidades, lugares geograficamente determinados, na comunidade de fluxos, dentro da sociedade da informação?

- Como as cidades podem propor planos para usufruir a instalação de empresas da economia de informação em benefício de uma região urbana?

A sociedade informacional abre mão da proximidade de fontes de matéria-prima, fontes de energia, mão-de-obra abundante e mercado consumidor contíguo (PORTER, 1993; MUMFORD, 1982). No início da industrialização, a necessidade de matéria-prima e fontes de energia em locais adjacentes impulsionou o desenvolvimento de regiões industriais nas cercanias de minas de carvão (energia) e de minérios (matéria-prima). As cidades tornaram-se, então, organização ideal para o provimento de mão-de-obra ou mercado - de forma que Henri Lefebvre (1999) prognosticou que o fenômeno urbano tenderia a ser universal, estando na base, portanto, de importantes discussões futuras de Manuel Castells (Sociedade da Informação) e Saskia Sassen (Cidades Mundiais), por exemplo.

Porém, a economia de base informacional e os arranjos geopolíticos contemporâneos tendem, de um lado, a tornar as indústrias independentes de proximidade com insumos físicos ou reserva de mão-de-obra e, de outro, a facilitar a circulação de mercadorias e profissionais - so- bretudo aqueles ligados ao desenvolvimento de produtos tecnológicos digitais. Se Manuel Castells (1996, p. 375) afirma que "o espaço de fluxos substitui o espaço dos lugares", que continuariam importantes para a concretização de transformações econômicas globais mas perderiam seu significado cultural, geográfico e histórico, Félix Guattari (1986) ressalta que as cidades perderiam sua importância por qualidades particulares para se converterem em nós de uma rede multidimensional de processos técnicos, científicos e artísticos, mas concentrariam e atrairiam as pessoas responsáveis pela "produção da subjetividade", isto é, pela germinação da criatividade cultural, tecnológica e econômica que animaria a sociedade informacional.

As cidades, assim, mantêm seu papel por serem "formadas e formadoras da diversidade, atratoras e dispersoras de valores que nelas se transformam" (DUARTE, 2002). E tais qualidades, que mais que se perpetuam, revigoramse em alguns lugares, são o destaque que Peter Hall (1995) coloca à luz ao dizer que Londres, Paris, Barcelona, Milão ou Roma (restringindo-se ao continente europeu) são importantes dínamos sociais há mais de 2 mil anos, cuja força está tanto em possíveis características físicas quanto na dinâmica de fatores políticos, culturais, econômicos, financeiros, sociais e técnicos. Assim, as empresas e pessoas inovadoras dependem de um ambiente informacionalmente rico e esse ambiente está intimamente ligado às qualidades do contexto urbano.

Com essa análise, busca-se responder à primeira pergunta que guia este estudo, destacando a importância permanente das cidades na rede de fluxos, dentro da sociedade da informação.

Passa-se, então, à segunda questão: como as cidades podem propor planos para usufruir a instalação de empresas da economia de informação em benefício a uma região urbana?

\section{OS AGLOMERADOS E O MEIO URBANO}

A constituição de pólos tecnológicos é um dos primeiros arranjos urbanos próprios da sociedade da informação. A exemplo de Silicon Valley, nos Estados Unidos, ou Sophia-Antipolis, na França, os primeiros pólos tecnológicos foram implantados a distâncias médias de grandes centros urbanos e foram, até certo ponto, responsáveis pelo desenvolvimento de suas respectivas regiões (CASTELLS; HALL, 1994).

A concentração de fatores positivos para o desenvolvimento tecnológico está ligada a um conjunto de aspec- 
tos políticos, intelectuais, financeiros, tecnológicos, sociais e culturais. Os lugares que os possuem articulados podem ser considerados "informacionalmente ricos". A partir dos anos 70, início do desenvolvimento do que ora se chamam tecnologias de informação, o modelo nacional foi substituído por outro, o das regiões, onde se desenvolveram os tecnopolos, formados nas proximidades de cidades que possuíam atrativos econômicos e culturais, mas com estrutura urbana independente, e que serviam, como escreveram Georges Benko e Alain Lipietz (2000), como articulação entre as economias nacional e internacional.

Philippe Aydalot (1985) analisa que desde os anos 80 as inovações tecnológicas privilegiam um desenvolvimento descentralizado em que os atrativos das cidades (e não mais as nações ou macrorregiões infranacionais) têm força para imantar empresas inovadoras. Poder-se-ia dizer que isso ocorre tanto por sua base tecnológica, social e intelectual mais maleável a essas transformações quanto pela autonomia (relativa às organizações territoriais maiores) que têm para se colocarem na rede de inter-relações comerciais e intelectuais do espaço de fluxos.

Nos últimos anos, exemplos como os ambientes inovadores de Nova Iorque e Montreal demonstram que um número crescente de pólos tecnológicos é implantado em regiões internas ou centrais nas cidades, tendo, portanto, ligação estreita com a dinâmica socioeconômica e política urbana.

Para analisar a dinâmica econômica dos pólos tecnológicos, Michael Porter (1999, p. 211) define como aglomerados as "concentrações geográficas de empresas e indústrias concorrentes, complementares ou interdependentes que realizam negócios entre si e/ou possuem necessidades comuns de tecnologia, pessoas, infra-estrutura", com cinco principais características que beneficiariam as empresas participantes:

- acesso a insumos e pessoal especializado;

- acesso a informações técnicas e de mercado;

- complementaridade entre negócios;

- acesso a instituições e bens públicos, o que reduziria, entre outros, os custos com treinamentos;

- incentivos e mensuração de desempenho.

Também são cinco as condições apontadas por Roberto Spolidoro (1997) como necessárias para a efetivação de uma tecnópole:

- instituições de ensino superior e de pesquisa;

- mercado e políticas governamentais;
- condições empresariais favoráveis, com procedimentos administrativos simplificados e eficientes;

- ambiente propício à inovação, indo da infra-estrutura à diversidade cultural;

- iniciativas locais, advindas da comunidade local e regional.

Essas duas perspectivas podem ser complementares, mas apresentam dois enfoques que merecem ser destacados: Porter atém-se aos aspectos internos do pólo, às características que otimizariam os arranjos produtivos locais, enquanto Spolidoro trata das características do contexto onde os pólos podem surgir e vingar. Esses dois pontos de vista, complementares, estão sempre presentes na literatura sobre os aglomerados e sinalizam uma possível ordem para a efetivação de um pólo tecnológico, que seria:

- conjunto de qualidades infra-estruturais, científicas, socioeconômicas e políticas, pré-existentes ou induzidas em uma região, que cria condições para a implantação de um pólo;

- conjunto de apoios e instrumentos institucionais na região que facilite a organização empresarial a fim de otimizar os arranjos produtivos do pólo.

Do modelo de complexos industriais (como Silicon Valley, Estados Unidos), às cidades da ciência, aos parques tecnológicos (como Sophia-Antipolis, França) e às tecnópoles (Japão), em todos os casos Castells e Hall (1994, p. 31-33) mostram que o foco está na consolidação ou constituição de condições favoráveis ao desenvolvimento de pólos tecnológicos cujas externalidades à região contígua estão, sobretudo, voltadas ao crescimento industrial e econômico.

Todos, porém, apontam que as sinergias ótimas que impulsionariam os pólos não devem se restringir às empresas envolvidas diretamente na cadeia de produção; ou seja, além das relações mais imediatas entre as empresas envolvidas no desenvolvimento de um mesmo produto, os aglomerados ${ }^{1}$ possibilitam as cadeias produtivas paralelas e se beneficiam delas. Tais cadeias vão desde a realização de pesquisas agrícolas e a indústria de equipamentos até a consolidação do mercado turístico e gastronômico e de centros universitários.

Apesar disso, o que se vê na literatura é que essas complementaridades estão sempre voltadas à otimização produtiva dos diferentes arranjos e setores econômicos. Maria Elizabeth Lunardi (1997) elenca as três principais características de um parque tecnológico implantado em 
meio urbano: as ligações formais com universidades e instituições de pesquisa; o crescimento de empresas de outras bases tecnológicas implantadas na região; a coordenação por entidade com funções gerenciais, estimulando ações voltadas à capacitação das empresas do pólo e também das outras instaladas na região. Em se tratando de pólos inseridos em meio urbano, as ações urbanísticas estão comumente voltadas à preparação do terreno para atrair e otimizar os arranjos produtivos, com raras exceções prognosticando as conseqüências da implantação dos pólos como fomento de novas ações de política urbana.

Tendo-se destacado que as cidades têm um papel fundamental como ambiente informacionalmente rico e propício ao desenvolvimento de pólos de inovação, colocase a pergunta: quais medidas de planejamento e gestão são possíveis para otimizar valores de um contexto urbano central de modo a atrair a implantação de um pólo de inovação tecnológica e torná-lo, ao mesmo tempo, catalisador de requalificação urbana?

\section{ESTUDO DE CASO: CIDADE MULTIMÍDIA, MONTREAL}

No final da década de 90, a província de Quebec, no Canadá, iniciou a implementação de uma grande política de desenvolvimento tecnológico com um diferencial importante: seu vínculo estreito com o desenvolvimento de áreas urbanas centrais que passavam por um processo de degradação.

Atento às oportunidades globais do mercado de software, à fuga de talentos jovens da área de informática para os Estados Unidos e ao potencial tecnológico interno existente, o governo do Quebec lançou no início de 1997 a política dos Centros de Desenvolvimento de Tecnologia de Informação - CDTI, apoiada em medidas legais e financeiras. Em menos de um ano, mais de 200 empresas já haviam se cadastrado no programa.

Antes de partir para o estudo de caso da Cidade Multimídia, de Montreal, é importante entender a posição do Canadá em relação aos parâmetros de inovação tecnológica no mundo, sua indústria interna e a decisão política de privilegiar esse setor.

\section{Inovação Tecnológica - Fatores Institucionais e Territoriais}

É certo que o mercado global e interconectado é uma realidade cada vez mais presente nas diretrizes das em- presas ligadas à tecnologia, seja na aquisição de novos processos e produtos, seja na abertura de mercado. Mesmo com essa influência direta no desempenho das empresas, as escalas nacional e local também têm papel fundamental no seu desenvolvimento - e como já se ressaltou, a inovação tecnológica está fortemente atrelada ao ambiente em que as empresas estão inseridas (PORTER, 1999; SPOLIDORO, 1997), onde se materializam um possível ambiente institucional propício à inovação e redes formais e informais entre empresas do mesmo setor.

Nesse sentido, Joe Tidd, John Bessant e Keith Pavitt (1997) consideram que os fatores mais influentes no sucesso do setor industrial ligado à inovação tecnológica são a posição em relação aos competidores e a existência de um sistema nacional de inovação. O primeiro indício do sistema nacional pode ser visto pelo porcentual do PIB ligado à pesquisa e ao desenvolvimento - P\&D. O Japão, por exemplo, apresentou crescimento de $0,85 \%$ do PIB ligado a P\&D, em 1967, para 1,9\%, em 1993. Nos Estados Unidos, essa taxa passou, no mesmo período, de 0,99\% para $1,45 \%$; e no Canadá, esses números foram de $0,40 \%$ a $0,58 \%$.

TABELA 1

PIB Investido em Pesquisa e Desenvolvimento Países selecionados da OECD - 1999 Em porcentagem

\begin{tabular}{lc}
\hline País & PIB Investido em P\&D \\
\hline Suécia & 3,80 \\
Japão & 3,04 \\
Estados Unidos & 2,64 \\
Alemanha & 2,44 \\
França & 2,17 \\
Reino Unido & 1,87 \\
Canadá & 1,77 \\
Itália & 1,04 \\
\hline
\end{tabular}

Fonte: OECD (2001).

Comparando os dados anteriores de Japão, Estados Unidos e Canadá com os da Tabela 1, percebe-se que houve crescimento expressivo de investimentos em P\&D em todos os países, sendo que a média dos países desenvolvidos é de 2,2\% (CALAMAI, 2002).

A defasagem dos investimentos canadenses levou o governo a criar o programa Innovation Strategy, que almeja elevar o índice de investimento em P\&D à casa dos $3 \%$ até 2010 - chegando a taxas similares às projetadas 
para os países que mais investem em tecnologia (Finlândia, Islândia, Suécia, Japão e Estados Unidos) e também ao compromisso assumido pelos países da União Européia (CANADÁ, 2002). Esse incremento tem apoio em programa de governo nacional que envolve também empresas privadas e universidades.

Na província de Quebec, as diretrizes incluem investimento em empresas tecnológicas iniciantes; adoção de práticas de gestão avançadas; acesso dessas empresas a serviços especializados de transferência tecnológica; desenvolvimento e marketing para os produtos criados. Todas essas iniciativas passam por uma diretriz governamental geral: a de que "O desenvolvimento de uma cultura de inovação nos negócios é central para uma visão moderna do desenvolvimento econômico regional" (CANADÁ, 2002, tradução do autor).

\section{Indústria Multimídia no Canadá}

Desde a década de 90 o Canadá vem investindo de modo sistemático na indústria das tecnologias de informação e um dos destaques é a indústria multimídia, que pode ser considerada uma combinação da indústria cultural e de entretenimento com a indústria da informática e abrange desde o desenvolvimento de equipamentos eletrônicos e programas específicos a design de portais web e jogos eletrônicos.

O desenvolvimento dessa indústria conta com uma base consumidora nacional crescente. De acordo com pesquisa da consultoria ACNielsen (1999), realizada entre 1996 e 1999 , sabe-se que $11 \%$ de canadenses efetuaram compras on-line em 1996, número que chegou a 25\% em 1999.

As empresas privadas são os maiores consumidores da indústria multimídia, seguidas da educação, que gera $20 \%$ da receita dessa indústria, os consumidores individuais $(13 \%)$ e o governo $(10 \%)$. Um detalhe importante é que $53 \%$ das empresas também vendem seus produtos para os Estados Unidos.

Os créditos governamentais auxiliam no desenvolvimento de dois terços das empresas e crescem a oferta e a procura por crédito internacional - considerado estratégico por $61 \%$ das empresas.

Uma de suas principais características é a configuração em micro e pequenas empresas, sendo que $37 \%$ têm menos de 5 empregados, $40 \%$ entre 6 e 25 e $6 \%$ contam com mais de 100 trabalhadores, sendo que as principais funções são de criação ( $26 \%$ dos empregados), técnicos $(22 \%)$ e administração e vendas $(20 \%)$. O fato de haver sobretudo pequenas empresas reforça os dados levantados por Stéphane Dion (2001, p. 17), segundo os quais as parcerias são cruciais nessa área, tanto no desenvolvimento de produtos, no marketing e nas vendas quanto no acesso a tecnologia e na distribuição de produtos.

O relacionamento estreito entre as empresas é fundamental para seu crescimento, abrangendo da rivalidade competitiva à colaboração - critérios importantes para pesquisa e desenvolvimento de indústrias ligadas à inovação tecnológica estudadas por J. Tidd, J. Bessant e K. Pavitt (1997). E é nesse sentido que a configuração em clusters torna-se decisiva (PORTER, 1999). Os clusters são marcados por proximidade geográfica entre empresas (fornecedores, indústria e acesso a mercados), autonomia das indústrias para buscar soluções e criar mercados, independentemente de uma estrutura piramidal de grandes corporações, e conexões próximas entre as empresas, sejam formais ou informais.

No Canadá, três clusters ligados à indústria multimídia têm destaque: Vancouver, Toronto e Montreal - não por acaso, centros de importantes aglomerados urbanos onde se encontram desde centros de pesquisa e formação de profissionais das áreas de criação, técnica, administrativa e marketing, até os principais mercados internos, distribuídos tanto geograficamente (Toronto e Montreal no extremo leste, Vancouver no extremo oeste) quanto culturalmente (Toronto e Vancouver de cultura anglófona, Montreal, francófona), como também pela proximidade com os Estados Unidos.

Assim, a província de Quebec estabeleceu um vínculo rápido com o mercado francês, tanto pela proximidade lingüística quanto pela distância de tecnologia de software (por exemplo, a França vivia os estertores de um sistema próprio de redes de computadores por via telefônica, o Minitel). Nessa época, a província de Quebec contava mais de 3 mil empresas de desenvolvimento de softwares com produtos nas áreas de comércio, saúde, educação, construção civil, etc.

Em um estudo conduzido pela British Trade International (1999), a indústria multimídia do Quebec aparece como a mais dinâmica e inovadora do Canadá - e a Cidade Multimídia de Montreal é seu centro. Resgatando as características sintéticas dos clusters, nota-se que no programa da Cidade Multimídia outros fatores estão explicitamente presentes. No lado institucional, uma das características citadas como das mais importantes pelo seu sucesso, segundo a British Trade International, consiste na articulação de organizações como a Associação 
de Produtores de Multimídia do Quebec - APMQ, o Centro de Promoção do Software do Quebec - CPLQ e a Alliance NumeriQC, que dão suporte para o desenvolvimento e a promoção das empresas ligadas a multimídia. Quanto à autonomia das empresas, o programa de incentivos do Centro de Desenvolvimento de Tecnologias de Informação - CDTI tem como pré-requisito que as integrantes sejam novas, portanto com liberdade de decisão, sem passar por grandes corporações. Ademais, as trocas de informações em ambientes informais estão suportadas por um empreendimento urbanístico que privilegia a mistura de usos em uma área restrita, de unidades das universidades locais aos edifícios de escritório, dos cafés aos edifícios residenciais. Isso propicia um convívio intensivo entre os profissionais, por concentrar as empresas da área multimídia em um mesmo setor, como também um convívio extensivo, pela diversidade de usos que proporciona justamente a troca de informações em âmbito informal.

\section{Cidade Multimídia - Base Institucional}

A Cidade Multimídia ${ }^{2}$ poderia ser segmentada em três principais itens: a) um programa de ajuda fiscal a empresas ligadas às novas tecnologias; b) uma sociedade imobiliária destinada à construção de escritórios; c) um projeto urbanístico para recuperar um antigo bairro industrial de Montreal.

O programa de ajuda fiscal exibia um caráter eminentemente do governo da província, para alavancar a indústria ligada às tecnologias de informação, em especial a multimídia, de telecomunicações, de sistemas de informação e de software, sob coordenação do organismo Investissement Québec (www.invest-quebec.com/en/ accueil.jsp).

Iniciado em 1997 e concluído em 2003, o programa institucional do CDTI foi destinado às empresas ligadas à inovação tecnológica e teve o objetivo explícito de

reunir corporações em edifícios específicos para encorajar a criação de redes tecnológicas para maximizar a sinergia e cooperação e ao mesmo tempo oferecer-lhes facilidades adaptadas às suas necessidades (QUEBEC, 2003).

Foram designadas cinco localidades onde os centros se desenvolveriam: Gatineua, Sherbrooke, Laval, Quebec e Montreal. Seguem as principais características desse programa institucional de incentivo à inovação tecnológica.
Os benefícios fiscais:

- cinco anos de isenção de impostos sobre lucro, capital e para o fundo de saúde dos empregados;

- 40\% de abatimento como crédito em taxas ligadas aos salários dos empregados;

- 40\% de abatimento como crédito em taxas ligadas a compra ou aluguel de equipamentos especializados.

Para ter acesso ao programa, as empresas deveriam: - submeter projeto enquadrado em setor emergente da indústria das tecnologias de informação e comunicação (multimídia, software, telecomunicações, etc.);

- comprometer-se em desenvolver expertise em sua área de atuação;

- ser novas e ter como único negócio o desenvolvimento de projetos de inovação tecnológica;

- desenvolver todas ou quase todas as atividades nos locais indicados;

- realizar atividades que gerassem novos negócios para a província de Quebec.

Foram considerados projetos inovadores:

- investigação com objetivo de formar novos conhecimentos técnicos ou científicos;

- pesquisa aplicada, com objeto claro e aplicação prática, ou pesquisa pura;

- ou ainda a estruturação comercial de conhecimentos e inovações tecnológicas prévias que ainda não estivessem no mercado.

Os empregados contados para os benefícios fiscais deveriam ter as seguintes características:

- contrato de pelo menos 26 horas semanais, por um período mínimo de 40 semanas;

- função que permitisse sua especialização em um setor emergente;

- no mínimo 50\% do tempo de trabalho cumprido na empresa;

- no mínimo 90\% do horário de trabalho envolvido nos projetos de inovação.

Em Montreal, o programa dedicou-se especialmente às empresas emergentes ligadas à indústria multimídia, daí Cidade Multimídia para a região onde foi implantado.

$\mathrm{Na}$ Cidade Multimídia, 46\% das empresas estão voltadas ao desenvolvimento e design em multimídia, 13\% são provedores de Internet, 17\% dedicam-se ao desenvolvimento de equipamentos e softwares e $32 \%$ são de servi- 
ços. Hoje, trabalham nesse pólo mais de 6 mil pessoas nos $121 \mathrm{mil} \mathrm{m}^{2}$ de edificações para escritórios, com salários médios 50\% superiores aos da média de Montreal; de 700 a 800 pessoas vivem nos edifícios residenciais construídos ou revitalizados no bairro histórico, que tem sua recuperação quase completa.

A articulação entre organismos públicos, privados e setoriais teve como principais participantes os seguintes atores e atividades:

- Cité Multimédia, promotor imobiliário;

- Cidade de Montreal, especialmente pelos organismos SDM, sociedade paramunicipal; SITQ, banco de investimentos; SOLIM, fundo dos trabalhadores de Quebec;

- governo de Quebec, com Investissement Québec, programa de apoio fiscal; Ministério do Meio Ambiente, para recuperação de terrenos contaminados na área portuária e industrial; Ministério de Assuntos Municipais e Metropolitanos, com investimento em infra-estrutura;

- organismos sem fins lucrativos, como CEIM, incubadora de empresas, e Quartier Éphémère, que se encarregou da recuperação e transformação da Fundição Darling em centro de artes;

- sociedades privadas, como Gueymard e McGill, com projeto para a Universidade McGill, e Prével, com o projeto Quai de la Commune.

\section{Processo Urbano da Cidade Multimídia}

New ideas need old buildings.

Jane Jacobs

Com as mudanças tecnológicas no complexo industrial (da produção aos meios de distribuição, dos produtos aos mercados), várias indústrias importantes deixaram a cidade de Montreal, instalando-se na vizinha Laval, junto às rodovias - o mesmo padrão de implantação regional e urbanístico encontrados em parques industriais ao redor do mundo (ROBITAILLE; ROY, 1998). ${ }^{3}$

Como as novas empresas ligadas às tecnologias de informação não produziam máquinas, não encontravam brechas para se aproveitar dos incentivos fiscais e também não usufruíam a sinergia científica e tecnológica dos parques industriais - um dos quesitos de sucesso dos aglomerados. Elas foram, então, abrindo mão dos parques industriais e instalando-se em outras regiões urbanas.

Como notaram Éric Robitaille e Philippe Roy (1998, tradução do autor), "as empresas do setor de multimídia e novas mídias tendem a buscar localização mais central" do que as grandes indústrias que requeriam grandes plantas industriais.

Uma das diretrizes do programa CDTI é instalar essas empresas em edifícios desocupados em áreas urbanas centrais, que costumam ter infra-estrutura disponível (não só eletricidade, água, esgoto, mas também cabeamento óptico, retransmissores celulares, etc.), são servidas por transporte público de massa e possuem redes de equipamentos urbanos complementares (de cafés a faculdades). Todavia, elas passam por um processo de esvaziamento crescente - e quando são recuperadas, na maioria das vezes é com expressivo montante de dinheiro público com empreendimentos que formam edificações, mas raramente conseguem trazer ocupantes constantes e diversificados (empresas, comércio e habitação) de volta às áreas centrais.

Nos 121 mil metros quadrados de escritórios da Cidade Multimídia trabalham mais de 6 mil pessoas, com idade média de 32 anos e salários acima da média de Montreal. Unidades das principais universidades da cidade foram inauguradas ou ampliadas na região e a chegada desses trabalhadores e estudantes impulsionou o mercado imobiliário residencial a construir cerca de 500 unidades habitacionais onde vivem aproximadamente 800 pessoas - além de dezenas de empreendimentos comerciais e de serviços (de restaurantes a oficinas gráficas) que se instalaram dando apoio cotidiano à Cidade Multimídia.

Tanto por meio dos incentivos fiscais quanto na recuperação de áreas urbanas, o governo investiu milhões de dólares. Se já de início tais medidas provocaram reação negativa de setores da sociedade (de jornalistas a pesquisadores), tal fato se agravou com o estouro da bolha ponto com, no início dos anos 2000. As críticas foram ferozes, mas circunstanciais: entre o estouro da bolha e o abalo do modo de sustentação tecnológica da sociedade contemporânea, apenas alguns anos foram necessários para que a retomada econômica se apresentasse vigorosa. Assim, a previsão do governo de Quebec de investir na consolidação da Cidade Multimídia por dez anos, quando os edifícios deveriam ser vendidos, foi antecipada. Em 2004 (seis anos após o lançamento do programa), sete das oito fases do empreendimento foram vendidas à iniciativa privada por quase 150 milhões de dólares canadenses. Tal valor superou o investimento governamental, lembrando que a cidade ainda recolhe mais de CN\$ 7 milhões anuais de impostos com esses edifícios (LE DEVOIR, 2004). 
Tais benefícios financeiros deveriam ganhar relevância por serem provenientes de um desenvolvimento tecnológico de incentivo à retenção de talentos e de formação e consolidação de empresas locais de desenvolvimento de software. Há, contudo, um outro benefício que constitui o motivo pelo qual a Cidade Multimídia é estudada neste trabalho: os aspectos urbanos do projeto, articulando os desenvolvimentos tecnológico, científico e urbanístico da cidade.

\section{Política Tecnológica e Política Urbana}

Comentando as eventuais políticas fiscais do governo de Quebec para incentivar a industrialização, Pierre Desrochers (2002) combate a idéia de vincular ajuda fiscal à implantação de empresas de tecnologia em determinados locais, ressaltando que se isso implica a concentração de desenvolvimento imobiliário em uma região, ao mesmo tempo implica o não-investimento (ou mesmo o esvaziamento e a desvalorização) em outras áreas. Seu foco principal de crítica são as cidades industriais, que se distanciam do meio urbano, enquanto algumas áreas urbanas, pelos seus próprios atrativos e sinergias, apresentam espontaneamente o vicejo de um desenvolvimento econômico temático, citando, entre sete áreas em Montreal em 1998, a Cidade Multimídia. Não obstante, Desrochers critica, embasado por outros estudiosos do desenvolvimento econômico canadense, a "territorialização" de benefícios fiscais: se o foco é incentivar o desenvolvimento econômico, os incentivos deveriam valer para as empresas, independentemente das regiões de implantação.

Entre os dados utilizados por Desrochers e da crítica por ele formulada, para este estudo torna-se relevante destacar que: focando apenas o lado econômico do desenvolvimento tecnológico, a localização das empresas cabe apenas a elas; a região que recebeu a Cidade Multimídia já conhecia uma fomentação de empresas tecnológicas.

Aqui, discorda-se do primeiro aspecto, visto que, por vezes, a territorialização induzida traz outros benefícios, que não se restringem ao setor econômico diretamente envolvido com as empresas de tecnologia. Para sustentar tal discordância e apresentar um outro ponto de vista, focaliza-se a região onde a Cidade Multimídia foi implantada: no bairro Faubourg des Récollets, antiga região portuária de Montreal que perdeu importância quando o canal Lachine foi fechado, causando seu esvaziamento funcio- nal - indústrias e depósitos abandonaram os galpões e barracões que ocupavam, instalando-se alhures. ${ }^{4}$

Apesar desse esvaziamento, o bairro é adjacente ao centro histórico de Montreal (Vieux-Montréal). Com suas docas recuperadas com museus, circos, bares, etc., ele recebe milhares de turistas anualmente, além de abrigar o distrito financeiro e administrativo da cidade. Portanto, Faubourg apresentava dezenas de edifícios vazios em região bem servida de infra-estrutura e serviços urbanos. Várias tentativas governamentais de recuperação foram feitas em vão. Atentos às qualidades urbanas da região, no final dos anos 90 havia no bairro cerca de 150 pequenas empresas ligadas a moda, design, publicidade e à incipiente indústria multimídia.

Dessa forma, a escolha do bairro para se tornar a Cidade Multimídia atrelou ganhos tecnológicos e econômicos aos urbanos. As empresas que ali se instalaram, além de incentivos fiscais desde que cumprissem regras de formação e retenção de talentos científicos, artísticos e tecnológicos, beneficiaram-se também de um contexto urbano bem servido de infra-estrutura e serviços. Em contraponto, a cidade de Montreal viu um bairro central em processo de esvaziamento ser revigorado com custo que seria pago em período máximo de dez anos (como já esclarecido, isso aconteceu antes).

O governo de Quebec (por meio de agências de capital misto) investiu não apenas no fomento de um segmento econômico, mas também em um projeto de reestruturação urbana. Por conseguinte, não parece conveniente argumentar sobre as políticas de incentivos estritamente por seus aspectos tecnológico e econômico: os custos de recuperação do bairro Faugbourg des Récollets hora ou outra incidiria exclusivamente como despesa nas finanças públicas (raros são os projetos de recuperação de áreas centrais onde o poder público não é o grande, senão único, financiador).

Além disso, os incentivos e investimentos do governo na Cidade Multimídia referiram-se exclusivamente às empresas ligadas à atividade fim (desenvolvimento de aplicativos multimídia), não abarcando todas as demais que se instalaram na região, dando apoio às empresas e aos profissionais que passaram a viver no bairro, dos restaurantes aos empreendimentos residenciais, das unidades universitárias aos prestadores de serviços gráficos e às galerias. Enfim, empresas, empregados, prestadores de serviços, estudantes e moradores que passaram a vivenciar a região 24 horas por dia, sete dias por semana. A revitalização do bairro, do ponto de vista arquitetônico, 
contou com a recuperação de edifícios antigos e construção de novos, em um contraste estimulante entre dois tempos de pujança econômica do local: a região portuária e o bairro das novas tecnologias.

Nesse sentido, o projeto Cidade Multimídia deve ser analisado pela diversidade de questões que traçaram seus objetivos desde o início:

- uma política regional de desenvolvimento tecnológico;

- ênfase em um setor da economia tecnológica, cuidando das sinergias empresariais necessárias;

- aspectos de desenvolvimento humano e científico da região (com formação e retenção de talentos como parte das condicionantes à cessão de benefícios às empresas);

- a análise urbana buscando identificar regiões que apresentassem potencial incipiente para esse setor empresarial tecnológico (como visto, foram identificadas sete, em Montreal);

- a estratégia de usar uma política de desenvolvimento empresarial tecnológico para catalisar a recuperação de uma área urbana.

Se os três primeiros itens são comuns às recomendações para o desenvolvimento de pólos tecnológicos, os últimos itens diferenciam o projeto da Cidade Multimídia - se não pelo seu caráter inaugural, ao menos pelo sucesso que obteve. Em quase todos os pólos, os motivos de localização são levantados, mesmo que signifiquem a repetição de modelos tanto empresariais quanto urbanísticos, como a implantação de centros de desenvolvimento de softwares junto a parques industriais.

Em análise financeira estrita, o investimento pagou-se alguns anos antes do previsto. Porém, se o espectro analítico fosse ampliado, incluindo a estratégia urbana subjacente ao empreendimento, um bairro histórico central em decadência, adjacente a áreas nobres, acaba recuperado não apenas pela remodelação de seu conjunto edilício, mas por, efetivamente, voltar a ser usado pela cidade, retornando à cena socioeconômica urbana de Montreal.

\section{CONCLUSÕES}

Considerando a reflexão inicial sobre as cidades na sociedade informacional, o contraponto entre sociedade de fluxo e localidades fixas não retira do meio urbano o potencial de ser um dos nós no espaço de fluxos, um dos dínamos dessa sociedade, pois são ao mesmo tempo seu pólo centrípeto, por atrair bens, pessoas e signos de di- versas fontes, e centrífugo, por emanar esses mesmos elementos pelo espaço.

Algumas cidades elaboraram estratégias para serem catalisadoras de inovações tecnológicas na sociedade de informação, articulando atores públicos e privados - órgãos públicos, empresas e universidades. Pode-se dizer que a constituição de pólos tecnológicos é um dos primeiros arranjos urbanos próprios da sociedade da informação. Se antes a sua maioria era implantada nas regiões periféricas às cidades, com formato semelhante a parques industriais, hoje os pólos de inovação, espontâneos ou induzidos, consolidam-se em áreas urbanas "ricamente informadas" - com infra-estrutura tecnológica, social, econômica, cultural e científica.

Os resultados desta pesquisa, utilizando como estudo de caso a Cidade Multimídia, em Montreal, ampliaram os parâmetros de análise dos pólos tecnológicos incorporando referenciais estratégicos de gestão urbana, de modo que as cidades deixem de ser o receptáculo passivo e informe de atividades econômicas e tecnológicas vigorosas para se tornarem agentes capazes de oferecer ambiente ativo e informado para esse desenvolvimento.

A cidade-palco é substituída pela cidade-atriz, que se envolve em processos de negociação, planejamento e gestão urbana e regional, aliando seus trunfos de catalisadoras de inovação científica às suas necessidades de recuperação urbanística de determinadas áreas.

Por fim, propôs-se com este estudo que as análises de aglomerados e pólos não apenas citem os aspectos locacionais como importantes para o sucesso das sinergias empresariais, colocando as avaliações sempre do ponto de vista dos aglomerados, mas ensaie críticas e forme base conceitual, metodológica e referencial para analisar o sucesso de arranjos produtivos do ponto de vista das cidades: como elas tornam-se agentes nesse processo, o que oferecem, quais benefícios colhem. Enquanto o sucesso da primeira análise foca os resultados empresariais, a segunda permite ver os resultados urbanos, os quais se espraiam por segmentos da sociedade que, mesmo não estando ligados às empresas dos pólos, usufruem seus ganhos urbanísticos.

\section{NOTAS}

1. Os aglomerados, termo usado nas traduções da obra de Michael Porter e aqui adotado, aparecem também como clusters ou ambientes de inovação.

2. Ver detalhes em: <http://www.citemultimedia.com>. 
3. Ver detalhes em: <http://www.citemultimedia.com/english/a Propos/galeriaPhotos.asp $>$.

4. Ver detalhes em: <http://www.citemultimedia.com/english/a Propos/ galeriaPhotos.asp $>$.

\section{REFERÊNCIAS BIBLIOGRÁFICAS}

ACNIELSEN-DJC. Research. Profil de l'industrie du multimédia au Canada. Toronto, 1999.

AYDALOT, P. Économie regionale et urbaine. Paris: Economica, 1985.

BENKO, G.; LIPIETZ, A. (Org.). La richesse des régions. La nouvelle géographie socio-économique. Paris: Presses Universitaires de France, 2000 .

BRITISH TRADE INTERNATIONAL. Multimedia in Canada, partnership opportunities for UK and Canadian companies. Toronto: BTI, 1999.

CALAMAI, P. Budget first step towards a national science policy. Opinion Canada, Montreal, v. 4, n. 10, CRIC, janv. 2002.

CANADÁ. Science and Technology Advice: A Framework to Build On. Reports on Federal Science and Technology. Ottawa, 2002.

Disponível em: <www.innovation.gc.ca>.

CASTELLS, M. The information age: economy, society and culture. Malden: Blackwell, 1996. 3 v.

CASTELLS, M.; HALL, P. Las tecnópolis del mundo: la formación de los complejos industriales des siglo XXI. Madrid: Alianza Editorial, 1994.

DESROCHERS, P. Les 'cités': une politique efficace pour la nouvelle économie? Cahiers de Recherche Montreal, Montreal, Institut Économique de Montréal, févr. 2002.

DION, S. Profile of the Canadian multimedia industry. Montreal: Industry Canada, 2001.

DUARTE, F. Do átomo ao bit. São Paulo: Annablume, 2003.

. Crise das matrizes espaciais. São Paulo: Perspectiva, 2002.

Arquitetura e tecnologias da informação. São Paulo: Annablume/Fapesp, 1999. na, 1998 .

Global e local no mundo contemporâneo. São Paulo: Moder-

GUATTARI, F. Questionnaire. In: CRARY, J.; FEHER, M.; FOSTER, H.; KWINTER, S. (Ed.). Zone 1/2. The Contemporary City. New York: Zone Books, 1986. 460p.

GUEDES, M.; FORMICA, P. A economia dos parques tecnológicos. Rio de Janeiro: Anprotec, 1997.
HALL, P. Cidades do amanhã. São Paulo: Perspectiva, 1995.

LE DEVOIR. La Cité Multimédia est vendue. Montreal, 22 de janv. 2004.

LEFEBVRE, H. A revolução urbana. Belo Horizonte: UFMG, 1999.

LUNARDI, M. E. Parques tecnológicos: estratégias de localização em Porto Alegre, Florianópolis e Curitiba. Curitiba: Edição do autor, 1997.

MUMFORD, L. A cidade na história. Brasília: Martins Fontes e UnB, 1982.

OECD. Science, Technology and Industry Scoreboard. Paris: 2001.

PORTER, M. Competição: estratégias competitivas essenciais. Rio de Janeiro: Campus, 1999. Campus, 1993

A vantagem competitiva das nações. Rio de Janeiro:

QUEBEC. CDTI - Information Technologies Development Centres. Investissement Québec, 2003. Disponível em : <www.investquebec.com/en/que/doc/cdti.jsp>. 1998.

Ministère des Finances du Québec. Communiqué. 5 nov.

Gouvernement du Québec. Centre de développement des technologies de l'information. Dossier spécial. Disponível em: $<$ www.cdti.gouv.qc.ca $>$.

ROBITAILlE, E.; ROY, P. Analyse de l'industrie du multimédia à Montréal et à Paris. Montreal: Université de Montréal, 1998.

SANTOS, M. Técnica, espaço e tempo. Globalização e meio técnicocientífico-informacional. São Paulo: Hucitec, 1996.

SPOLIDORO, R. A sociedade do conhecimento e seus impactos no meio urbano. In: PALADINO, G.; MEDEIROS, L. (Org.). Parques tecnológicos e meio urbano. Brasília: Anprotec, 1997.

TIDD, J.; BESSANT, J.; PAVITT, K. Managing Innovation. Integrating technological, market and organizational change. West Sussex: John Wiley and Sons, 1997.

Fábio Duarte: Urbanista. Doutor em Comunicações. Professor em Gestão Urbana da PUC-PR. Autor do livro Crise das matrizes espaciais entre outros (duarte.fabio@pucpr.br).

Artigo recebido em 1 de fevereiro de 2005. Aprovado em 4 de abril de 2005. 